\title{
Are People with Disabilities Losing the ICT Revolution? Some Evidence on European Countries
}

\author{
María Rosalía Vicente* and Ana Jesús López
}

Department of Applied Economics, University of Oviedo, 33006-Asturias, Spain

\begin{abstract}
This paper contributes to the line of research devoted to the diffusion of Information and Communication Technologies. We analyse patterns of Internet diffusion across people with disabilities in ten European countries, a geographical area for which empirical evidence is scarce. Results show that disability status has a significant negative effect on the probability of being an Internet user, even for those with higher income and educational attainment. However, we find no significant relationship between disability and frequency of Internet use. Therefore, it seems that once online the digital divide between people with disabilities and the rest of the population attenuate, at least to some extent.
\end{abstract}

Keywords: Internet, information and communication technologies (ICT), disability, digital divide, logit regression.

\section{INTRODUCTION}

Over the last years Information and Communication Technologies (ICT) have been recognized to open up great possibilities for economic growth, competitiveness, and human development. Therefore, ICT diffusion has become an element of strategic importance to all countries [1].

Moreover, recent research in the United States has drawn attention on the potential economic benefits from broadband deployment to an important group of population: the elderly and people with disabilities. In particular, Litan [2] estimates an economic benefit of at least $\$ 927$ billion in 2005 dollars over the next 25 years, coming from lower medical costs, delay of institutionalized living, and additional output generated by more seniors and individuals with disabilities in the labour force.

In spite of these benefits, figures show that people with disabilities have only half the rate of Internet access of individuals without impairments $[3,4]$. In fact, there is a vicious circle between ICT and disability. On the one hand, individuals with impairments are much less likely to be in employment than the rest of the population, and when they get a job, it is usually a low-wage and low-skilled one which does not allow them to afford ICT. On the other hand, people with disabilities face many accessibility problems that prevent them to use ICT, and therefore to gain the necessary digital skills in order to get a high-skilled job.

Within this context, the analysis of patterns of Internet diffusion among people with disabilities has emerged as a central issue. Therefore, we have tried to assess the importance of disability status for both Internet take up and frequency of usage across some European countries, a

*Address correspondence to this author at the Department of Applied Economics, Campus del Cristo s/n, University of Oviedo, 33006-Asturias, Spain; Tel: + 349851050 53; Fax: + 349851050 50; E-mail: mrosalia@uniovi.es geographical area for which empirical evidence is quite scarce. With this aim we present our methodological framework (section 2). This is followed by a discussion of the findings (section 3) and the paper ends with some concluding remarks (section 4).

\section{METHODOLOGY}

In order to examine to what extent disability constitutes a significant barrier to using the Internet, we have conducted some logit regressions in which the dependent variable is a binary indicator of whether an individual uses the Internet or not (user $=1$, non user $=0$ ), expressed as function of a linear combination of explanatory variables, including socioeconomic factors (income, age, educational attainment, gender, and employment) and disability status.

Assume that Internet use is determined by an unobserved latent variable,

$Y_{i}^{*}=X_{i}^{\prime} \beta+u_{i}$

for individual $\mathrm{i}, \mathrm{i}=1, \ldots, \mathrm{N}$. Only $Y_{i}$ is observed, which equals 1 if $Y_{i}^{*}>0$, implying that individual $i$ uses the Internet; $Y_{i}$ equals zero if individual $\mathrm{i}$ does not use the Internet. $X_{i}$ is a vector of decision-maker's attributes, and $\mathrm{u}_{\mathrm{i}}$ is the error term. Assuming that $\mathrm{u}_{\mathrm{i}}$ follows a logistic distribution, the data is described by the following logit model:

$P\left(Y_{i}=1\right)=\varphi\left(X_{i}^{\prime} \beta\right)$

where $\phi$ is the cumulative logistic distribution function.

Once determined whether disability status significantly influences an individual choice's to use the Internet, it will be interesting to analyse what happens when the individual is online. In particular, we explore whether disability status 
matters with regard to the frequency of Internet use. This variable is measured in a four-point scale from less to more frequency: (1) less than once a month; (2) at least once a month; (3) at least once a week; and (4) every day or almost every day. Given the nature of the dependent variable, ordinal logit regression seems to be the most appropriate technique. Similar to (1), we assume that the frequency of Internet use is determined by an unobserved latent variable,

$Z_{i}^{*}=X_{i}^{\prime} \gamma+\varepsilon_{i}$

where $X_{i}$ is a vector of explanatory variables, $\varepsilon_{i}$ is the error term, and $Z_{i}$ is:

$$
\mathrm{Z}_{i}=\left\{\begin{array}{l}
1 \text { if } Z_{i}^{*} \leq a_{1} \\
2 \text { if } a_{1}<Z_{i}^{*} \leq a_{2} \\
3 \text { if } a_{2}<Z_{i}^{*} \leq a_{3} \\
4 \text { if } Z_{i}^{*}>a_{3}
\end{array}\right.
$$

where $a_{j}(j=1,2,3)$ are threshold parameters and verify: $\mathrm{a}_{1}<\mathrm{a}_{2}<\mathrm{a}_{3}$.

Assuming that the random error $\varepsilon_{\mathrm{i}}$ follows a logistic distribution, the model can be estimated by means of an ordinal logistic regression.

\section{RESULTS}

This paper addresses the analysis of the disability digital divide using data from the project eUser [5], funded by the European Commission's IST (Information Society Technology) programme. The dataset contains information on individuals aged 15 and over, living in ten European countries (the Czech Republic, Denmark, France, Germany, Hungary, Ireland, Italy, Poland, Slovenia, and the United Kingdom). Data reports to the year 2005 with 9,807 interviews successfully completed. Disability identification is based on self-reporting by the interviewed ${ }^{\mathrm{i}}$. It is important to take into account the limitations of self-reporting disability [6]: in particular, people with similar conditions can disagree about whether that condition constitutes a disability, and whether they want to identify themselves as a person with a disability.

Table 1 presents the results for Internet use. All the variables are statistically significant. The first interesting point to note is that having a disability has a significant effect on the probability of being an Internet user. In particular findings suggest that when controlling for socioeconomic characteristics, people with disabilities are still less likely to use the Internet. Even for those with higher income and educational attainment, having a disability constitutes an important barrier to using the Internet.

The results for the rest of variables are in line with previous evidence on this field of research [7-11]. Hence, we find that those with higher income and educational attainment are more likely to be Internet users, as are those employed. Meanwhile the elderly and women are less likely to be online. It is worth noticing that the gender gap is bigger than the disability gap. If we reckon the inverse of the odds ratio $^{\text {ii }}$, we find that men are 1.5 times as likely to use the Internet as women; meanwhile, the probability of using the Internet, with respect to individuals with disabilities, is 1.2 times higher for those without impairments.

Table 1. Logit Regressions on Internet Use

\begin{tabular}{|c|c|c|}
\hline & Model 1 & Model 2 \\
\hline Intercept & $-1.607 * * *$ & $-0.324 * *$ \\
\hline Income 2 & $0.557 * * *$ & $0.502 * * *$ \\
\hline Income 3 & $1.070 * * *$ & $1.011 * * *$ \\
\hline Age: $25-49$ & $-2.093 * * *$ & $-2.067 * * *$ \\
\hline Age: $50-64$ & $-3.106^{* * *}$ & $-3.082 * * *$ \\
\hline Age: 65 and more & $-4.408 * * *$ & $-4.413 * * *$ \\
\hline High School Education & $0.412 * * *$ & $0.300 * * *$ \\
\hline College degree & $1.323 * * *$ & $1.278 * * *$ \\
\hline Post graduate Education & $2.277 * * *$ & $2.313 * * *$ \\
\hline Women & $-0.422 * * *$ & $-0.431 * * *$ \\
\hline Employed & $0.509 * * *$ & $0.518 * * *$ \\
\hline Has a disability & $-0.136^{*}$ & $-0.160 * *$ \\
\hline GDP & $0.014 * * *$ & \\
\hline R\&D expenditure & & $0.696 * * *$ \\
\hline IT expenditure & $0.403 * * *$ & \\
\hline Human Capital & $0.025 * * *$ & $0.039 * * *$ \\
\hline $\begin{array}{l}\text { Chi-square statistic } \\
\text { (Likelihood Test) }\end{array}$ & $4157.8 * * *$ & $4219.8 * * *$ \\
\hline Pseudo $\mathbf{R}^{2}$ & 0.506 & 0.508 \\
\hline Classification rate (\%) & 79.5 & 79.6 \\
\hline
\end{tabular}

Note: Figures reported are estimated coefficients.

Income 2 indicates an income between poverty threshold and median equivalised income. Income 3 indicates an income above median equivalised income.

For the estimation of the model we have considered the following reference groups: those below poverty threshold; those who are less than 24 years old; primary education; men; the unemployed; and those without disabilities.

*** Significant at the $1 \%$ level; ** significant at the $5 \%$ level; * significant at the $10 \%$ level.

Since our analysis is cross-country some macroeconomic variables related to the country of residence have been included. In particular, we have considered income per capita (Gross Domestic Product per capita, GDP), a measure of the efforts on research and development activities (R\&D expenditure as a percentage of GDP) as well as on information technologies (IT expenditure as a percentage of GDP), and an indicator of human capital (percentage of the adult 
population aged 25 to 64 participating in education and training) $)^{\text {iii }}$. Data comes from Eurostat [12]. Results show that all the macroeconomic variables are statistically significant with a positive sign. Interestingly, $R \& D$ expenditure comes as the most the powerful determinant of Internet use among these variables (note that it gets a coefficient 0.697) as previously shown by Vicente and López [13] in their analysis of ICT diffusion across the European Union.

Table 2 shows the results for the ordinal logit regression on Internet use frequency ${ }^{\text {iv }}$. We note that having a disability is not significant with regard to the number of times the individual uses the Internet, while the rest of the socioeconomic variables are significant and keep the sign previously observed in Table $\mathbf{1 .}$

Table 2. Ordinal Logit Regression on the Frequency of Internet Use

\begin{tabular}{|c|c|}
\hline & Model 1 \\
\hline$a_{1}$ & $-3.527 * * *$ \\
\hline $\mathrm{a}_{2}$ & $-2.317 * * *$ \\
\hline$a_{3}$ & $-0.502 * * *$ \\
\hline Income 2 & 0.101 \\
\hline Income 3 & $0.508 * * *$ \\
\hline Age: $25-49$ & $-0.210 * *$ \\
\hline Age: $50-64$ & $-0.436 * * *$ \\
\hline Age: 65 and more & $-0.890 * * *$ \\
\hline $\begin{array}{l}\text { High School } \\
\text { Education }\end{array}$ & -0.087 \\
\hline College degree & $0.403 * * *$ \\
\hline $\begin{array}{l}\text { Post graduate } \\
\text { Education }\end{array}$ & $0.875 * * *$ \\
\hline Women & $-0.505 * * *$ \\
\hline Employed & $0.215^{* * *}$ \\
\hline Has a disability & 0.035 \\
\hline $\begin{array}{l}\text { Chi-square statistic } \\
\text { (Likelihood Test) }\end{array}$ & $540.6 * * *$ \\
\hline Pseudo $\mathbf{R}^{2}$ & 0.1 \\
\hline
\end{tabular}

Note: See notes under Table 1.

\section{CONCLUDING REMARKS}

This paper has addressed the analysis of Internet diffusion among people with disabilities. The estimates show that those individuals with a disability are less likely to use the Internet, even when they have higher incomes and education. Such result should not be interpreted as an indication of people with disabilities being less capable to use the Internet; in fact it might be a sign of problems of accessibility when accessing to the Internet. Recent research has shown that only $5.3 \%$ of government websites and hardly any of the commercial websites in the European Union are fully compliant with the basic accessibility guidelines [14]. As a consequence, many people with disabilities just cannot access the Internet. However, this kind of barriers seems to attenuate once the individual is online. Hence, we find no significant differences in the frequency of use between people with disabilities and other Internet users. Therefore, our results suggest the need for einclusion strategies towards people with disabilities which focus on overcoming barriers of access and fostering web accessibility. In this sense, it would be useful to subsidize both the acquisition and the upgrade of ICT equipment and the adaptative technologies many people with disabilities need to use ICT. Given the increasing importance of broadband wireless, such subsidies should not focus on buying computers only but also on mobile devices that would allow people with disabilities to be online everywhere. In order to properly use these technologies, it is also necessary to improve the digital skills of this collective by means of e-alphabetization courses. Nonetheless, it is important to highlight that very little will come of all these efforts if they are not accompanied by a serious reinforcement of accessibility requirements through the implementation of legislative actions. Only in this way, European authorities will be able to fulfil the goal of $100 \%$ of accessible public websites by the year 2010 .

\section{REFERENCES}

[1] US Department of Commerce. A nation online: Entering the broadband age. Washington, D.C.: 2004.

[2] Litan RE. Broadband for seniors and disabled. Broadband Properties 2006; Feb: 24-35.

[3] Dobransky K, Hargittai E. The disability divide in Internet access and use. Inform Commun Soc 2006; 9: 313-34.

[4] Research and Training Center on Disability in Rural Communities. Disability and the Digital Divide: Comparing Surveys with Disability Data [Online]. Nov 15 2006; [cited 2006]. Available from: http://rtc.ruralinstitute.umt.edu/TelCom/Divide.htm

[5] eUSER. Public Online Services and User Orientation [Online]. Nov 10, 2005, [cited 2005]. Available from: http://www.euser-eu.org

[6] Cai L. Is self-reported disability status endogenous to labour force status? Appl Econ Lett 2009; 16: 459-64.

[7] Demoussis M, Giannakopoulos N. Facets of the digital divide in Europe: determination and extent of internet use. Econ Innovat New Technol 2006; 3: 235-46.

[8] Fairlie RW. Race and the digital divide. Contrib Econ Anal Policy 2004; 3: 1-38.

[9] Horrigan JB, Stolp C, Wilson RH. Broadband utilization in space: effects of population and economic structure. Inform Soc 2006; 22: 341-54.

[10] Vicente MR, López AJ. El empleo de las personas con discapacidad en la sociedad de la información: desafíos para los nuevos estados miembros. Estudios de Economía Aplicada 2007; 25: 429-46.

[11] Vicente MR, López AJ. Some empirical evidence on internet diffusion in the new member states and candidate countries of the European Union. Appl Econ Lett 2008; 15: 1015-8.

[12] Eurostat. Structural Indicators [Online]. Nov 10, 2008; [cited 2008]. Available from: http://epp.eurostat.ec.europa.eu

[13] Vicente MR, López AJ. Patterns of ICT diffusion across the European Union. Econ Lett 2006; 93: 45-51.

[14] Empirica and Work Research Center. Measuring e-accessibility in Europe. Brussels: European Commission 2007. 
[15] Greene WH. A statistical model for credit scoring. Working paper: Leonard N. Stern School of Business 1992; 29: 1-43.
[16] Heckman J. Sample selection bias as a specification error. Econometrica 1979; 47:153-61.

(C) Vicente and López; Licensee Bentham Open.

This is an open access article licensed under the terms of the Creative Commons Attribution Non-Commercial License (http: //creativecommons.org/licenses/by$\mathrm{nc} / 3.0 /$ ), which permits unrestricted, non-commercial use, distribution and reproduction in any medium, provided the work is properly cited.

${ }^{\mathrm{i}}$ The question that gauges disability status in the survey is phrased as follows: "Do you have any long-standing illness, disability or infirmity that limits your activities in any way? By long-standing I mean anything that has troubled you over a period of time or that is likely to affect you for a period of time".

ii The odds ratio is a measure of strength of association between variables, usually reported in logit regressions. It is reckoned for each variable as exp( $\beta$ ), where $\beta$ is the estimated coefficient. In this case, the inverse of the odds ratio is reckoned for an easier interpretation.

iii The R\&D variable is not included together with income and information technology variables due to their high correlations. Initially we had also included some measures of telecommunications costs (Internet access prices and phone call tariffs) but they were found not to be statistically significant.

iv This model was estimated using data on individuals reporting that they used the Internet. Since our data came from a sample of the full population, if we restricted our analysis only to those with Internet use, sample selection bias could be introduced. Therefore, we previously studied the existence of sample selection bias by adopting a two-stage estimation procedure $[15,16]$. Although we do not report results here, they showed that there was no sample selection bias. 